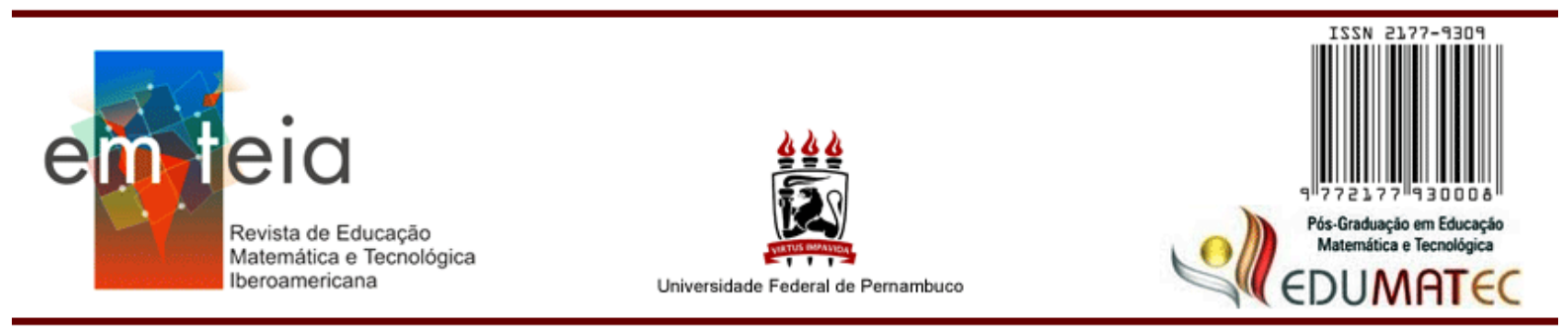

\title{
A AULA NÃO É MAIS PRESENCIAL, E AGORA? Tecnologias e experiências docentes em tempos de COVID-19
}

\author{
Keila Mendes dos Santos \\ Doutoranda PPGE - UFAL \\ Professora da Universidade do Estado da Bahia - UNEB \\ keumendes@hotmail.com
}

\begin{abstract}
Resumo
A pandemia do coronavírus trouxe uma nova realidade para o contexto educacional com a transposição das aulas presenciais para modelos não presenciais em todos os níveis de ensino. No âmbito educacional, os docentes se viram repentinamente tendo que adaptar suas práticas, o que evidenciou desafios distintos. Partindo deste contexto, o estudo ora proposto tem por objetivo investigar as experiências educativas vivenciadas pelos professores e os seus posicionamentos ao terem que migrar suas aulas do contexto presencial para o ensino remoto, observando as principais problemáticas, como também os aspectos que favoreceram o processo de ensino e aprendizagem. Trata-se de uma pesquisa qualitativa, configurada como estudo de caso, tendo como participantes oito professores de língua inglesa da educação básica. Os dados foram coletados via questionário elaborado no Google formulários e os links enviados aos participantes pelo aplicativo WhatsApp. Os resultados apontam que, apesar dos desafios do primeiro impacto com a nova modalidade, principalmente na descoberta e utilização de melhores recursos, como também problemas envolvendo formação, conexão e participação dos alunos nas aulas, estes vêm se adaptando gradativamente ao novo contexto.
\end{abstract}

Palavras-chave: pandemia, coronavírus, ensino remoto, língua inglesa, desafios.

\begin{abstract}
The coronavirus pandemic presented a new reality to the educational context with the transposition of face-to-face classes to non-face-to-face models in all levels of education. In the educational field, teachers suddenly found themselves adapting their practices, which highlighted challenges from different natures. Based on this context, the study proposed aims at investigating teachers' educational experiences and their positions when they have to migrate their classes to remote teaching, observing the main problems and the positive aspects in the teaching and learning process. This is a qualitative research, configured as a case study. The participants were eight English teachers from the basic education. The data were collected through a questionnaire created on Google forms and the link sent to the participants via WhatsApp. The results show that, despite the challenges of the first impact with the new modality, mainly in the discovery and use of better resources, as well as problems involving teacher's training, connection and students' participation in classes, they have been gradually adapting to the new context.
\end{abstract}

Keywords: pandemic, coronavirus, remote teaching, English language, challenges. 


\section{Introdução}

O início de 2020 nos surpreendeu com a propagação do vírus SARS-CoV-2, o coronavírus, que desencadeou a COVID-19, em um processo de contaminação de proporções pandêmicas. Tal fato fez com que todas as atividades envolvendo aglomerações, a exemplo de shows, viagens, jogos, competições esportivas, como também bares, restaurantes, escolas e uma diversidade de setores, tivessem seu funcionamento suspenso em um primeiro momento, voltando a funcionar posteriormente mediante adoção de medidas restritivas.

No Brasil, apesar de ainda não termos voltado à "normalidade", pois o retorno de todas as atividades demanda uma vacina contra o vírus, temos vivenciado o que se convencionou chamar de "novo normal". Neste cenário, as tecnologias digitais desempenham papel fundamental na mediação das relações, uma vez que a nossa interação presencial está comprometida.

Embora o isolamento social tenha sido vivenciado em outras pandemias ao longo dos séculos como medida preventiva para evitar a propagação de doenças, esse se caracterizava como momento solitário, sem comunicação com quem estivesse distante, o que não é predominante no contexto atual, conforme enfatizam Couto, Couto e Cruz (2020). Ao apresentarem um breve histórico das maiores pandemias já ocorridas, os autores destacam a conectividade favorecida pelas tecnologias digitais em rede como um grande diferencial, pois, por meio delas, podemos interagir virtualmente, trabalhar, estudar, desempenhar uma diversidade de atividades. Neste sentido, Henrique (2020) ressalta que o que temos vivenciado não se trata de isolamento social e sim de um distanciamento físico, conceito que adotaremos neste estudo, tendo em vista que as tecnologias digitais têm mediado nossas relações sociais com nossos pares.

Cabe salientar que esse acesso às tecnologias não alcança a todos de maneira igualitária, sendo inevitável suscitar o debate que envolve a democratização do seu acesso. Por se caracterizarem como recursos mediadores em vários âmbitos durante a pandemia, a falta de acesso a tecnologias, em especial à internet, pode conduzir a outros tipos de desigualdade e, ainda, exclusão social, educacional, digital, etc.

Essa diferença no acesso às tecnologias dividiu opiniões com relação à continuidade das aulas com mediação tecnológica, devido ao fato de muitos alunos, principalmente da rede pública de ensino, não possuírem acesso à internet banda larga, computadores ou mesmo espaço 
em casa para a realização dos estudos, sendo o celular o instrumento mais utilizado para a comunicação, segundo a pesquisa TIC domicílios 2019.

Considerando que a função da escola não se limita apenas a transmitir conteúdos, mas também contribuir para a formação social, tornou-se uma ação inviável silenciar a educação em um momento em que o conhecimento, propagação de saberes, informações e orientação para a seleção de conteúdos verídicos com base científica são de suma importância.

Neste sentido, ao reconhecer que a escola e a educação, de maneira mais ampla, desempenham papel fundamental em tempos de crise, e que mantê-la sem funcionamento em um momento tão delicado pode suscitar desigualdades ainda maiores, além de retrocesso no desenvolvimento de habilidades e ampliação do índice de evasão escolar, conforme destaca a portaria $\mathrm{n}^{\circ} 544$ do MEC (BRASIL, 2020), pensamento também corroborado por Arruda (2020), muitas medidas foram adotadas para que os aprendizes tivessem algum tipo de acesso a atividades educativas, formais ou não, durante o período de suspensão das aulas presenciais.

Este contato com as atividades educativas se materializou de diversas formas, no intuito de alcançar o maior número de alunos, envolvendo desde o envio de materiais impressos a serem retirados nas escolas, teleaulas via canais de televisão e o formato mais expressivo, o ensino remoto, com aulas síncronas por meio de plataformas de videoconferência.

Assim, no âmbito educacional, os docentes, se viram repentinamente tendo que migrar suas práticas para contextos não presenciais. Tal fato evidenciou desafios de naturezas distintas como a falta de preparo docente para atuar em contextos mediados por tecnologias digitais, uma vez que não houve momento formativo, nem planejamento para tal. Presenciamos também a necessidade de orientação para os aprendizes que, apesar de utilizarem recursos tecnológicos diversos em seu dia a dia, não estavam acostumados ao uso destes com fins educativos ou pedagógicos.

Podemos observar, frente ao cenário exposto, que os desafios têm sido diversos, visto que, após um primeiro período de grandes adaptações, percebemos, ainda mais, a necessidade de revermos a formação docente, inicial e continuada, e as práticas de ensinar e aprender na cultura digital. Cabe salientar que a necessidade de transformações no processo de formação de professores para uso das tecnologias digitais da informação e comunicação (TDIC) não surgiu em decorrência das demandas do ensino remoto emergencial, pois já vem sendo debatida e estudada há alguns anos.

Diante dos desafios e das lacunas apresentadas no processo de formação de professores para ensinar com a mediação tecnológica ou em ambientes não presenciais, e de como estes 
profissionais têm se reinventado para se adaptar à nova realidade, neste estudo, temos por objetivo investigar as distintas experiências educativas vivenciadas pelos professores e os seus posicionamentos ao terem que migrar suas aulas do contexto presencial para o ensino remoto, observando as principais problemáticas encontradas nesta transição, como também os aspectos que favoreceram o processo de ensino e aprendizagem. Para tanto, partimos do seguinte questionamento: quais as experiências e percepções docentes perante o desafio de migrar suas aulas, inesperadamente, do contexto presencial para o online devido à pandemia da COVID19? Trata-se de uma pesquisa qualitativa, configurada como estudo de caso, realizada entre julho e agosto de 2020, tendo como participantes oito professores de língua inglesa da educação básica. Os dados foram coletados via questionário elaborado no Google formulários e enviados aos participantes pelo aplicativo WhatsApp.

O estudo foi conduzido em diálogo com documentos do MEC e CNE, e com o aporte teórico que aborda a temática, e está organizado em três seções, além da introdução e das considerações finais. Na primeira seção, são apresentadas algumas distinções entre ensino remoto, EAD e educação online; na segunda, é feito um breve histórico do ensino de língua inglesa (LI) com ênfase nas principais tecnologias adotadas por cada método e, na terceira seção, na etapa metodológica, são realizadas a análise e a discussão dos dados obtidos com a aplicação dos questionários.

\section{Ensino remoto? Ead? Educação online? Algumas considerações conceituais}

A pandemia do coronavírus trouxe uma nova realidade para o contexto educacional com a transposição das aulas presenciais para modelos não presenciais em todos os níveis de ensino. Apesar da Lei de Diretrizes e Base da Educação (LDB) estabelecer no seu art. 32 que a oferta do ensino fundamental deva ser presencial, o mesmo artigo também afirma que esta poderá ocorrer na modalidade à distância em situações emergenciais (BRASIL, 1996). Neste sentido, com a impossibilidade de retorno às aulas com presença física nas escolas, o MEC e o CNE, por meio de portarias (Portaria $n^{\circ} 544$, BRASIL, 2020) e pareceres (Parecer CNE n5/2020) autorizaram o funcionamento das aulas remotas com mediação de tecnologias para todas as instituições de ensino como medida emergencial, podendo as aulas ministradas contabilizarem a carga horária anual obrigatória.

O novo formato das aulas, por ter sido adotado de maneira repentina, recebeu diversas nomenclaturas como educação a distância (EAD), educação online e ensino remoto 
emergencial, que passou a ser mais utilizado para caracterizar o atual contexto. Considerando que o decreto $\mathrm{n}^{\mathrm{o}}$ 5.622/2005 (BRASIL, 2005), que regulamenta a EAD no Brasil, a conceitua como uma modalidade de educação mediada por tecnologias da informação e comunicação em que estudantes e professores estão em tempos e espaços diferenciados, podemos considerar que todos os conceitos aqui apresentados são formas de se operacionalizar a educação a distância enquanto modalidade não presencial. No entanto, as concepções de ensino e aprendizagem que norteiam cada um deles faz com que sejam necessários maiores esclarecimentos entre os termos. Isto posto, faremos, nesta seção, uma distinção entre os conceitos de EAD, educação online e ensino remoto.

A EAD, modalidade reconhecida legalmente no Brasil pela LDB em 1996, apesar de só ser regulamentada em 2005 pelo decreto $n^{\circ}$ 5.622/2005 (BRASIL, 2005), teve início com cursos por correspondência, nos quais o recebimento e envio de material, assim como toda a comunicação entre aluno e professor, eram realizados via correios, com a mediação de material impresso.

Ao longo das décadas, outros recursos tecnológicos foram utilizados na EAD como o rádio e a televisão, ou seja, tecnologias de massa, impulsionando uma perspectiva transmissiva e massiva de educação, na qual não ocorria interação entre professores e estudantes, havendo maior ênfase no autoestudo. Os cursos ministrados visavam à formação técnica e profissional de adultos, a exemplo dos que eram ofertados por programas como o Instituto Universal Brasileiro e o Telecurso 2000 (SANTOS; BURCI, 2017; CAMPUS, 2020).

Em fases posteriores, a EAD passa a contar com uso de computadores, a princípio não conectados à internet, fazendo uso de materiais via CDs e DVD. Com a internet, a EAD adota modelos mais interativos com a possibilidade de participação do aluno em fóruns, chats, postagens nos ambientes virtuais de aprendizagem e uma diversidade de recursos e atividades que podem ser propostos a depender do desenho didático adotado pelos cursos.

Além de ser instituída e regulamentada com bases legais, a adoção da EAD deve envolver alguns aspectos como planejamento, conteúdos organizados em módulos ou capítulos, materiais didáticos e avaliação adequada, devendo ainda contar com profissionais qualificados para atuar na modalidade (CIEB, 2020). Partindo dessas prerrogativas, podemos perceber algumas diferenças entre o ensino remoto em vigência e a EAD, uma vez que não houve tempo para planejamento, formação docente, ou preparação de materiais e recursos para adaptação ao novo contexto. 
$\mathrm{O}$ ensino remoto emergencial foi uma medida temporária adotada para atender às demandas educacionais dos estudantes e docentes em distanciamento físico, como salientam Moreira e Schlemmer (2020), e Alves (2020). Ao tratarem do ensino remoto, os autores destacam que a palavra remota está relacionada a algo distante geograficamente, sendo conceituado como uma modalidade de ensino que pressupõe professores e alunos separados fisicamente, na qual os modelos de currículo, práticas pedagógicas, metodologias e conteúdos adotados no presencial são utilizados em contextos online sem alterações, mediados por tecnologias digitais.

Nos formatos mais adotados, principalmente por instituições privadas de ensino, as aulas são ministradas conforme agenda de horários e conteúdos do presencial, optando por plataformas de webconferências síncronas. Conforme pontuam Moreira e Schlemmer (2020, p. 9):

O processo é centrado no conteúdo, que é ministrado pelo mesmo professor da aula presencial física. Embora haja um distanciamento geográfico, privilegia-se o compartilhamento de um mesmo tempo [...]. A comunicação é predominantemente bidirecional, do tipo um para muitos, no qual o professor protagoniza vídeo-aula ou realiza uma aula expositiva por meio de sistemas de webconferência.

Assim, as plataformas de webconferências, que já eram bastante utilizadas no mercado corporativo para comunicação e reuniões entre empresas, passam a ser ressignificadas no contexto educacional, no qual, até então, tinham pouca visibilidade, o que tem incitado a competição entre plataformas mais populares como a Teams da Microsoft, Google Meet e Zoom, aspectos pontuados nos estudos de Alves (2020).

Em suas considerações sobre o ensino remoto, Santos (2020) enfatiza que o ciberespaço é subutilizado nesta modalidade, ao priorizar o uso síncrono de plataformas de webconferência para promover o encontro de professores e alunos. Logo, acaba limitando o momento que poderia se prolongar em discussões assíncronas em ambientes virtuais de aprendizagem por meio de fóruns de discussão ou outras produções dos alunos.

Além da utilização das plataformas de videconferência, algumas instituições de ensino têm feito uso de transmissões via canal de televisão, materiais impressos e disponibilização de recursos em repositórios, com o fito de alcançar os alunos sem acesso à internet, ou que possuem internet de baixa qualidade. Campus (2020) sintetiza, em seus estudos, as principais diferenças entre o ensino remoto e a EAD, como podemos visualizar no quadro abaixo: 
Quadro 1 - Principais diferenças entre o ensino remoto e a EAD

\begin{tabular}{|l|l|}
\hline \multicolumn{1}{|c|}{ Educação a Distância } & \multicolumn{1}{c|}{ Ensino Remoto } \\
Flexibilidade espaço temporal & Sincronicidade \\
Planejamento com antecedência & Pouco ou nenhum planejamento \\
Apoio de tutores em horários dispersos & Apoio do professor seguindo a grade horária \\
Público alvo: adultos & Público alvo: Todos os estudantes sem aulas \\
& (crianças, jovens e adultos) \\
Autonomia & Envolvimento da familia \\
Planos autorizados & Planos emergenciais \\
Metodologia própria & Metodologia adaptada do ensino presencial \\
Presença pela realização de atividades & Presença obrigatória \\
& \\
\hline
\end{tabular}

Fonte: Campus (2020).

O quadro comparativo entre as duas modalidades evidencia suas particularidades, evitando que haja confusão na utilização dos conceitos. No entanto, Moreira e Schlemmer (2020) ponderam que o ensino remoto não tem por objetivo reinventar a educação, por se tratar de uma solução provisória para um contexto de emergência, sendo pertinente pensar a mediação tecnológica mais efetiva para um contexto pós-pandemia, de maneira que extrapole a transposição de modelos presenciais, a exemplo da educação online.

Para Santos (2019), a educação online não se configura uma nova etapa ou uma evolução da EAD, conceituando-a como um fenômeno da cibercultura, ou seja, da cultura que vivenciamos atualmente, amplamente mediada por tecnologias digitais. A modalidade pode ser ofertada de maneira síncrona ou assíncrona, mesclando o presencial com o não presencial em modelos híbridos de educação.

Nesse sentido, educação online é outra perspectiva de educação não presencial que demanda não apenas a utilização de tecnologias digitais em rede, mas também uma nova concepção de educação, currículo, metodologias e práticas pedagógicas, provocando uma mudança de paradigma (MOREIRA; SCHLEMMER, 2020). Conforme avaliam os autores, por partir da lógica das redes de aprendizagem, a educação online se pauta na dialogia, colaboração e autoria, tendo a interação como centro do processo educativo.

Dessa maneira, embora o ensino remoto venha atendendo às necessidades momentâneas, é preciso avançar rumo a práticas educativas que utilizem as tecnologias digitais de forma a promover uma educação inovadora, o que demanda formação docente para atuar em novos contextos. O momento da atual crise, segundo Arruda (2020), pode ser percebido como uma possibilidade de instigar uma formação tecnológica que não se limite ao consumo, provocando autorias e utilização crítica, acelerando uma atualização das práticas educativas que vinha ocorrendo de maneira vagarosa. 
Um aspecto pertinente destacado por Pretto, Bonilla e Sena (2020) é a importância de pensarmos a formação docente e discente para uso pedagógico das tecnologias digitais em paralelo ao desenvolvimento das políticas de acesso. Tal atitude evitaria o impasse de se ter recursos, mas não dispor de sujeitos aptos a utilizá-las, ou de termos profissionais qualificados que não dispõem de recursos.

Como as tecnologias digitais estão em rápido e constante processo de atualização, é necessário que a formação docente seja um ato contínuo, acompanhando as demandas sociais. Os autores destacam ainda que não é possível aguardar condições ideais para a promoção de práticas mediadas por tecnologias digitais, pois sempre haverá problemáticas a serem sanadas. Portanto, é pertinente que as várias instâncias se mobilizem simultaneamente e não esperem que um problema seja resolvido de cada vez, pois formação docente e discente, preparação tecnológica das instituições e as políticas de acesso são ações interdependentes.

\section{Breve histórico do ensino de li e as tecnologias mais adotadas em cada método}

Ao observamos o histórico do ensino de língua inglesa, podemos perceber que este é marcado por constantes transformações em métodos de ensino, sendo estas mudanças envoltas, também, no uso das tecnologias disponíveis em cada período histórico. Desta forma, considerando que, neste estudo, nos atentaremos às percepções de professores de língua inglesa (LI) sobre o processo de transição para o ensino remoto emergencial e suas experiências com uso de interfaces e tecnologias digitais distintas, cabem aqui algumas considerações sobre o papel das tecnologias ao longo da história do ensino de LI em seus diversos métodos, traçando uma trajetória histórico-evolutiva até chegarmos ao contexto atual.

Por serem diversos os métodos de ensino, estando alguns ainda em uso e outros com pouca visibilidade, nos atentaremos à observação e apresentação daqueles que se destacaram ao longo das décadas. Cabe salientar que, apesar de tentar estabelecer períodos históricos em que os métodos emergiram ou deixaram de ser usados, não implica no desaparecimento de métodos anteriores, pois muitos deles coexistiram ou ainda coexistem. Assim, serão apresentados o método gramática-tradução, o método direto e a abordagem comunicativa, destacando as principais tecnologias adotadas em cada um.

O método gramática-tradução, um dos mais antigos no ensino de línguas, surgiu nos estudos do latim, e passou a ser utilizado, posteriormente, no ensino de outras línguas. O método prioriza o aprendizado de regras gramaticais e a memorização de vocabulário. Como 
tecnologias mediadoras, eram adotados livros, principalmente os literários, e o quadro negro, que era utilizado para explicações gramaticais, tradução de listas e resolução de exercícios (FINARDI; PORCINO, 2014; RAIMUNDO; SILVEIRA, 2017).

No método direto, deve-se utilizar a língua materna o mínimo possível, estimulando o uso da língua que se está aprendendo para se comunicar, principalmente oralmente. Desse modo, as aulas de língua inglesa são ministradas também em inglês, mesmo que dificulte ou impossibilite a compressão do aprendiz, que deve repetir frases para intensificar a pronúncia. O método direto, segundo Finardi e Porcino (2014), dialoga com métodos que surgiram posteriormente, como o método do exército e o audiolingualismo.

Os autores destacam que o método do exército teve sua origem no contexto da Segunda Guerra, também fundamentado na repetição de estruturas prontas, originando daí os famosos drills, em um processo de condicionamento baseado em estímulos e respostas. Os referidos métodos faziam uso de tecnologias diversas como gravuras, livro didático, gravadores, retroprojetores, CDs, fitas de vídeos, além do uso de gestos e linguagem corporal; enfim, uma variedade de recursos que levassem à compreensão da língua-alvo, evitando recorrer à língua materna.

Borges e Paiva (2011) ressaltam que, até a década de 60, o ensino de língua era baseando em uma perspectiva essencialmente estrutural, enfatizando o ensino de gramática e memorização de frases prontas. No entanto, muitos professores perceberam que, mesmo que os alunos soubessem elaborar sentenças gramaticalmente corretas, tinham inúmeras dificuldades de se comunicar na língua estudada, tendo início os primeiros estudos que visavam a um ensino menos instrumental e mais comunicativo.

$\mathrm{Na}$ abordagem comunicativa, uma das mais utilizadas atualmente no ensino de línguas, o objetivo maior é desenvolver a competência comunicativa, isto é, o ato de se comunicar em contextos variados, observando aspectos linguísticos e não linguísticos que envolvem a comunicação, sendo a língua considerada prática social (FINARDI; PORCINO, 2014). Desde o seu surgimento, os professores que adotam essa metodologia fazem uso de tecnologias diversas, como CDs, DVD, televisão, materiais autênticos que tiveram o acesso facilitado com a inserção do computador e internet, o que possibilitou também a interação com falantes do idioma em diversos lugares do globo.

Apesar da abordagem comunicativa ainda ser muito utilizada e adaptada a contextos distintos, a busca pelo "método ideal” conduziu, nas últimas décadas, ao despontar de métodos ecléticos e híbridos, nos quais são adotadas simultaneamente características de diversos 
métodos de acordo com a necessidade dos aprendizes. Neste contexto, o surgimento da web 2.0 caracterizou-se como fenômeno que veio situar o ensino de língua em um novo cenário com recursos e tecnologias interativas, que favorecem a criatividade, criação e elaboração de materiais por parte do professor (PAIVA, 2015, FINARDI; PORCINO, 2014).

No caso específico do ensino remoto emergencial, independente de métodos adotados, os professores de LI vêm buscando a utilização de recursos múltiplos para envolver os alunos nas aulas, como jogos, músicas, vídeos, slides interativos, como veremos na análise dos dados. As aulas são ministradas em plataformas de webconferências síncronas, tendo na internet, o computador e smartphones como tecnologias fundamentais para que essas ocorram.

Por meio deste breve relato histórico, é perceptível a presença de diferentes recursos tecnológicos no ensino de LI desde os primeiros métodos de ensino. Porém, a utilização das TDIC para a mediação da aprendizagem totalmente online, principalmente na educação básica, é uma situação nova para a maior parte dos docentes que atuam neste contexto. Desta forma, na seção metodológica, analisaremos as respostas dos questionários para compreender como os professores têm vivenciado o ensino remoto e o papel das tecnologias digitais ao longo deste percurso.

\section{Metodologia}

O estudo em questão é uma pesquisa qualitativa, na categoria de estudo de caso, por tencionar investigar as experiências dos participantes em seus contextos de atuação (YIN, 2003). Os dados foram coletados entre julho e agosto por meio de questionários elaborados com o Google formulários e enviados pelo aplicativo WhatsApp para docentes de língua inglesa que estão ministrando suas aulas na modalidade do ensino remoto. Foram enviados 10 questionários, entretanto, somente oito retornaram com as devidas respostas, sendo este o número de participantes do estudo.

Partindo da problemática que envolve as reações e percepções docentes perante o desafio de migrar suas aulas, inesperadamente, do contexto presencial para o online, por conta da pandemia da COVID-19, tivemos por objetivo investigar as experiências educativas vivenciadas pelos professores de língua inglesa com o ensino remoto, observando as principais problemáticas encontradas, como também os aspectos que favoreceram o processo de ensino e aprendizagem, destacando o papel mediador das tecnologias digitais ao longo do percurso. 
Para proceder à análise dos dados, organizamos quatro categorias, sendo elas: a) experiências docentes com o uso das tecnologias digitais; b) formação para uso das tecnologias digitais; c) desafios ao longo da transição para o ensino remoto; e d) contribuições da experiência com o ensino remoto para educação.

Cabe destacar que, em alguns momentos da análise, serão apresentados excertos das falas dos professores de forma direta, para melhor visualizarmos seus posicionamentos e sentimentos com relação à experiência que têm vivenciado, ao tempo em que em outros estabeleceremos diálogos de forma indireta. Por questões éticas, os participantes serão identificados por nomes fictícios a sua escolha, a saber: Rachel, João, Macarena, Roberto Santos, Alana, Elle Silva, Joana e Diana. Passaremos à análise dos dados considerando cada uma das categorias.

\section{Análise e discussão de dados}

a) Experiências docentes com o uso das tecnologias digitais

A transição repentina do ensino presencial para as aulas remotas provocou reações diversas por parte de familiares, discentes, gestores e principalmente de professores que passaram a adotar novas práticas e recursos para mediar o processo de ensino e aprendizagem. Neste estudo, ao questionarmos os professores sobre suas reações quando souberam que as aulas passariam a ser ofertadas remotamente, estes apresentaram posicionamentos diversos como: desespero (Rachel), pânico (Joana), um desafio diante do fato de não saber o que fazer (João e Macarena), apreensão quanto à receptividade e aceitação dos alunos (Alana) e insegurança (Diana). Uma das participantes, Elle Silva, otimista com o novo contexto, considerou que as aulas remotas seriam fantásticas para o professor devido à possibilidade de poder desenvolver práticas subsidiadas pelas tecnologias digitais.

Além destes posicionamentos, a resposta do professor Robertos Santos chama a atenção ao trazer uma variável extremamente significativa ao contexto que é a questão do desemprego que também se tornou realidade para muitos professores. Roberto Santos afirma que, com a possibilidade de poder continuar as suas aulas mesmo que remotamente, se sentiu

Roberto Santos: [...] aliviado em saber que continuaria trabalhando, nesse momento tão delicado em que muitas pessoas estavam perdendo seus empregos, mas muito apreensivo quanto a incerteza de como seriam essas aulas. 
A mídia tem noticiado vários casos, principalmente de universidades particulares que tiveram demissão em massa dos seus professores em meio à pandemia. Casos como da universidade UNINOVE e da Cruzeiro do Sul (CNN Brasil, 2020; EL País, 2020) são exemplos dessa situação, causando ainda mais angústia e preocupação aos docentes.

Com relação à receptividade dos alunos ao ensino remoto, os professores destacaram que estes, em princípio, mostraram-se dispersos, angustiados; outros não deram muita importância por pensarem que seria algo provisório, com duração de apenas algumas semanas, aguardando o retorno do presencial para dedicarem maior atenção aos estudos. No entanto, ao perceberem que a situação se prolongaria por tempo indeterminado passaram a se adaptar ao "novo normal", de maneira que, segundo os professores, atualmente estão mais receptivos à modalidade, sendo que uns estão se adaptando mais facilmente que outros.

Ao abordarem a participação dos aprendizes nas aulas de língua inglesa e os recursos que utilizam para promover a interação, os professores destacaram que utilizam vários artifícios para levar o aluno a se envolver nas aulas, desde o uso de jogos, músicas, filmes e brincadeiras, como também atividades individuais e coletivas por meio de recursos como câmeras, microfones, ou ainda espaços específicos para trabalhos em grupos e interação entre os aprendizes, disponíveis nas plataformas adotadas pelas instituições. Além disso, os professores têm buscado distintos meios de instigar o desenvolvimento das habilidades linguística dos alunos, conforme destacamos nos excertos abaixo, nos quais esses pontuam os recursos e as possíveis habilidades que podem ser contempladas com sua utilização:

Rachel: Músicas, vídeos, games.

João: Áudio de textos/diálogos disponível no site da FTD. Slides para projeção no Google meet.

Macarena: Slides com vocabulários/textos para o reading, áudios/músicas para o listening, o próprio microfone para o speaking e as atividades impressas/livro para o writing.

Roberto Santos: O aluno pratica as habilidades de listening durante a aula online pela plataforma com o professor e pelo aplicativo do celular, pratica o speaking com o atendimento individual que tem com o professor e grupos de conversação com os colegas, pratica o reading e writing durante as atividades de homework com o livro de atividades.

Alana: Músicas, vídeos e também explorando mais os textos do próprio livro do aluno. 
Elle Silva: Produções de vídeo (speaking), leitura durante a aula (reading and listening), mostrando vídeos (listening), atividades e trabalhos escritos (writing).

Joana: Sempre utilizo flashcards, diálogos contextualizados, jogos diversos por meio de compartilhamento de tela, vídeos e músicas.

Diana: Audiovisuais e recursos de multimídias

Como podemos observar nas falas dos professores, a adoção de novos recursos tecnológicos no ensino remoto não implicou no abandono do livro didático e demais materiais anteriormente adotados, vindo estes ampliar as opções que os docentes já dispunham para subsidiar suas aulas.

b) Formação para uso das tecnologias digitais

A carência de formação docente para uso das tecnologias digitais em práticas pedagógicas foi um dos grandes desafios a se enfrentar na repentina transição das aulas, de acordo com CIEB (2020) e Arruda (2020). Embora os professores sejam sujeitos atuantes na cultura digital, fazendo uso de interfaces e aplicativos diversos em seu cotidiano, este uso não pressupõe a apropriação dos recursos com fins pedagógicos, sendo necessário orientação não apenas docente, mas também discente para utilização de insumos que auxiliem na mediação do processo ensino e aprendizagem (PRETTO; BONILLA; SENA, 2020).

Com a adoção do ensino remoto, este certamente foi um tema que repercutiu em várias instituições de ensino, uma vez que docentes sem formação para atuar na educação não presencial tiveram que adaptar suas práticas, muitos sem suporte institucional e uma rede formativa consistente para auxiliá-lo, ou, até mesmo, sem recursos tecnológicos necessários, como computador, microfone e conexão banda larga, só para citar alguns.

Ao questionarmos os professores deste estudo sobre os recursos que tinham em suas residências para atuar com o ensino remoto e se precisaram investir financeiramente em equipamentos, cinco destes afirmaram que não houve a necessidade de investimentos financeiros com suporte tecnológico por possuírem aparatos que atendiam suas demandas apropriadamente. Todavia, a professora Macarena precisou comprar um computador, ao tempo em que Roberto Santos e Diana precisaram ampliar seu pacote de internet banda larga para conseguirem melhorar o desempenho das plataformas adotadas.

No que concerne à formação para uso das tecnologias digitais em suas práticas antes da pandemia, seis professores destacaram que a formação que tiveram ocorreu somente ao longo 
da licenciatura (os professores cursaram ou estão cursando a Licenciatura em Letras, Língua Inglesa) na disciplina Novas Tecnologias e João destaca que já cursou uma pós-graduação que o orientou para uso das tecnologias em educação. Apenas a professora Diana não havia passado por nenhum momento formativo para uso pedagógico das tecnologias digitais antes da pandemia.

Apesar da formação limitada que tiveram no contexto pré-pandemia, os professores (sete deles) já faziam uso das TDIC para mediar suas aulas com a utilização de sites, canais, aplicativos, além de recursos disponibilizados pelas editoras dos livros didáticos adotados pelas escolas. Embora essa mediação tecnológica já venha ocorrendo, mesmo que timidamente, por parte dos professores, utilizar as tecnologias como recurso nas aulas presenciais se diferencia da sua utilização ao transpor a prática presencial para um contexto não presencial, implicando em uma nova modalidade de ensino que requer planejamento e formação.

Dessa maneira, perguntamos aos docentes se as instituições de ensino nas quais atuam ofereceram algum momento formativo ou orientação para auxiliá-los na transição de formato das aulas. Apenas duas professoras afirmaram não ter recebido nenhuma proposta de formação por parte das escolas, tendo que buscar de maneira autônoma as melhores formas de se adaptar ao novo contexto. Os demais docentes tiveram formação para uso das plataformas adotadas, sendo elas Google Meet e Zoom. Além disso, editoras dos livros didáticos ofereceram capacitação aos docentes das escolas parceiras com cursos online, lives, reuniões, atendimento individual e orientação para uso dos métodos adotados pelas escolas com mediação das plataformas. Entretanto, mesmo recebendo este suporte, Rachel e Alana destacaram que esses momentos formativos ocorrerem de maneira elementar, com orientações básicas apenas.

Cabe destacar a fala de Joana, por ser a única docente a pontuar que a escola em que trabalha contratou um funcionário para criar e alimentar o site da instituição, fornecendo suporte técnico aos professores, aspecto extremamente pertinente, considerando que a atividade educativa e pedagógica não deve se limitar unicamente ao trabalho docente, cabendo ações de demais membros da equipe gestora e técnica das instituições, de maneira a viabilizar recursos e serviços para oportunizar o processo de ensino e aprendizagem.

c) Desafios ao longo da transição para o ensino remoto

Em face à nova realidade educacional no país, questionamos aos docentes se tiverem dificuldades com a transição do presencial para o não presencial e quais foram estas dificuldades. Conforme análise das respostas, percebemos que as principais problemáticas estão 
estritamente ligadas às questões técnicas de utilização, seleção e operacionalização das interfaces ao longo das aulas, havendo uma insegurança sobre quais recursos adotar e como utilizá-los de maneira a envolver os alunos nas aulas e despertar o interesse em participar, tendo em vista que muitos dos aprendizes a princípio mostraram-se dispersos.

A fala do professor Roberto Santos aponta uma questão relevante, visto que este, por se considerar familiarizado com ambientes e plataformas digitais, não esperava encontrar empecilhos em sua prática. Todavia, o professor destaca que se sentiu desafiado perante a situações com as quais se percebeu despreparado para lidar, inclusive a impossibilidade do uso da linguagem corporal tão presente no ensino de línguas. Em suas palavras:

Roberto Santos: Senti, particularmente, dificuldade no planejamento das aulas, a elaboração de atividades, a falta do body language, mesmo com o uso de ferramentas como a WebCam, muitos problemas de conectividade com a internet, muitas horas sentado na frente do computador. E além de tudo isso, toda essa pressão psicológica pela qual todos nós estamos passando, cheio de incertezas e medos. Não imaginava no início que encontraria tantas dificuldades.

A pressão psicológica pontuada pelo professor também é destacada nos estudos de Santos (2020), que enfatiza que o adoecimento docente físico e mental tem sido crescente durante este período de confinamento em que suas atividades profissionais estão intimamente associadas à sua vida pessoal e afazeres domésticos, passando longas horas sentado em frente às telas, seja para ministrar ou preparar suas atividades. Ademais, podemos observar, na fala de Roberto Santos, que mesmo os professores experientes no uso das TDIC e educação sentiramse desafiados com o novo cenário educacional, situação corroborada nos estudos de Moreira e Schlemmer (2020).

Diante das problemáticas encontradas, como alternativas para solucioná-las, os professores lançaram mão da pesquisa, busca por informações e a experimentação de novos recursos e sites, conforme apresentamos abaixo nas falas de Roberto, Alana e Joana:

Roberto Santos: Tenho tentado remediar todas essas dificuldades com um planejamento prévio bem elaborado, preparação do material, pesquisa, elaboração de atividades lúdicas e criativas que despertem o interesse dos alunos.

Alana: Pesquisei alternativas práticas no meu plano de aula, descobri alguns sites com jogos de vocabulário que me ajudaram a prender a atenção de alguns alunos, uso mais músicas e vídeos do que antes, pois é bem mais fácil quando não precisamos conectar equipamentos para isso, basta compartilhar a tela. 
Joana: [...] busquei informações por conta própria, com pesquisas on-line, assistindo tutorias na plataforma digital YouTube, entre outros. Embora, o intuito seja sanar algumas das dificuldades que tenho enfrentado durante este contexto atípico que estamos vivendo, tenho consciência, de que nós, professores, precisamos nos capacitar ainda mais no que tange aos recursos tecnológicos digitais.

É notável que a autonomia docente foi algo fundamental para superação das limitações encontradas, ao apresentarem atitudes de professores pesquisadores, que investigam a própria prática e ao identificarem os problemas, procuram meios de implementar melhorias (DEMO, 1996).

Um aspecto que vale ressaltar na fala de Alana é o fato desta afirmar que, com o ensino remoto, vem utilizando mais músicas e vídeos do que antes, por não demandar instalação de equipamentos. Nós, professores, sabemos que, muitas vezes, esse movimento acaba consumindo um bom tempo da aula, principalmente das aulas de línguas que já apresentam carga horária reduzida, isso quando a instituição dispõe dos recursos a serem instalados. Neste aspecto, a professora considera que a transposição nos formatos facilitou a apropriação e utilização dos referidos recursos.

Ainda abordando os aspectos problemáticos nas novas práticas, a carência de uma conexão de banda larga de qualidade e a falta de participação dos alunos nas aulas foram destacadas por muitos dos professores, como podemos observar abaixo, ao questionarmos quais os maiores desafios encontrados:

Rachel: Usar as ferramentas e atrair a atenção dos alunos.

João: Acho que somente o afastamento físico. Nós professores precisamos ter contato com nosso aluno. Ver de perto seu aprendizado.

Macarena: A conexão da internet. Pois, nós temos todos esses recursos, fazemos um excelente planos de aula, mas, quando chega no momento a sua execução a internet não funciona, cai no meio da aula, os vídeos/câmera/microfones ficam travando. Então pra mim este está sendo um desafio, contar com algo que não está no meu controle.

Roberto Santos: O maior desafio foi os problemas enfrentados com a conectividade de internet, ora por mim, ora pelos alunos. Interação dos alunos nas atividades de conversação e o acompanhamento na realização das atividades.

Alana: A pouca ou nenhuma participação de alguns alunos e a incerteza de que o aluno esteja realmente assistindo a aula, uma vez que a maioria permanecem com as câmeras desligadas. 
Elle Silva: Consegui a atenção daqueles que não eram muito interessados e não saber como "rebater" a desculpas relacionadas às falhas da internet ou celular/computador deles.

Joana: O maior desafio é lidar com os recursos sem capacitação, pois planejar aulas, produzir material, pesquisar músicas, jogos e brincadeiras já faz parte do meu dia a dia. Mas, além de todo este processo habitual, tenho que aprender sozinha, a trabalhar com diversos recursos digitais e, isso, além de tomar um bom tempo, causa frustração quando não consigo de imediato manusear tais ferramentas digitais.

Diana: Dificuldades de comunicação com alguns alunos, por não terem acesso à uma internet ou aparelho que atende as necessidades da plataforma, e também o distanciamento, pois os alunos em casa se sentem mais 'soltos', e ficam mais livres para fazer como querem.

Como podemos verificar, a qualidade de conexão à internet de professores e alunos nem sempre atende às demandas para acessar determinadas plataformas. As diferenças na qualidade da conexão de internet no Brasil são claramente evidenciadas no documentário Freenet, no qual são apresentadas, além de localidades totalmente sem acesso, divergências de conexão até mesmo entre bairros, com serviços da mesma operadora dentro de uma mesma cidade.

Em suas falas, os professores destacam a angústia de não saberem se o seu planejamento poderá ou não ser executado por problemas na conexão, tendo em vista que o ensino remoto se fundamenta, na maior parte dos casos, no uso síncrono de plataformas. Uma maneira de auxiliar na resolução desta demanda seria a utilização de recursos assíncronos. Contudo, devido ao fato de estarmos lidando com adolescentes e crianças, que, apesar de utilizarem as tecnologias em seu dia a dia, nem sempre têm autonomia para se apropriar destes recursos em seus estudos (ALVES, 2020), nem foram devidamente preparados para a oferta de aulas remotas, os discentes acabam dependendo do direcionamento e contato síncrono com o docente em substituição ao face a face. Logo, tornam-se relevantes estes momentos para interagir com colegas e professores.

d) Contribuições da experiência com o ensino remoto para educação

Os estudos abordando a utilização e contribuições das TDIC na educação já têm sido desenvolvidos há alguns anos. Entretanto, por várias razões, como as citadas em Alves (2020), envolvendo falta de acesso, infraestrutura das escolas, conexão e formação, a apropriação destes recursos no contexto escolar, principalmente na educação básica, ainda vinha caminhando a passos lentos. A pandemia e as demandas por um novo formato educacional aceleraram este processo, mesmo que de forma improvisada, como bem destaca Arruda (2020). Desta forma, 
perguntamos aos docentes quais as contribuições, os pontos positivos que a experiência com o ensino remoto trouxe para a sua prática e obtivemos as seguintes respostas:

Rachel: Uma atualização da sala de aula.

João: Sim. Nós professores precisávamos de "capacitação" tecnológica. Era necessário aprendermos mais sobre as tecnologias digitais para melhorar nossa prática

Macarena: Percebi que minhas aulas ficaram mais dinâmicas, pois, podemos ter acesso a todos os recursos possíveis tornando assim as nossas aulas mais interativas. Aquela fala que sempre ouvimos que as escolas não dão suportes tecnológicos não é mais possível ser dita. Os recursos estão todos a seu favor, basta saber explora-los e ter uma excelente conexão de internet.

Roberto Santos: Percebi a importância do professor mesmo nesse novo cenário de ensino virtual, e de como os alunos necessitam de uma interação social que favorece o processo de ensino-aprendizagem.

Alana: Passei a levar coisas diferentes para os meus alunos, algo que eu não fazia com tanta frequência quanto agora.

Elle Silva: Sim. Quanto a disciplina de uma língua estrangeira, as aulas remotas facilitaram muito ter um pouco mais contato com a língua estrangeira (vídeos, tradutores, áudios).

Joana: Avalio como ponto positivo, neste contexto, a inserção da comunidade escolar na cultura digital.

Diana: Tudo que é novo nos causa um certo desconforto no início, mas também sempre traz algo de bom para se aprender. Só o fato de conseguir lidar com isso já é um grande passo, e o professor precisa sempre está se atualizando e buscando fazer o melhor para ajudar o seu aluno. O ensino remoto tem grande parte positiva pois, seria ruim não poder dar continuidade as aulas

Apesar do momento de tensão e desafios, os professores afirmaram que o ensino remoto trouxe várias contribuições para a educação, desde uma atualização da sala de aula com a inserção das tecnologias digitais, mediando práticas mais dinâmicas ao reconhecimento do papel fundamental do professor, mesmo em contextos virtuais de aprendizagem. Os professores ressaltaram ainda que conheceram diversos recursos e interfaces que pretendem continuar utilizando em suas práticas ao retornarem às aulas presenciais, como a plataforma Zoom, o Google Meet e seus recursos, sites para jogos infantis, como o Bamboozle, sites como o Film English, que apresenta vídeos com planos de aula, além do Google formulário e canais no YouTube, apenas para citar alguns que foram mencionados. 
Neste sentido, Pretto, Bonilla e Sena (2020) salientam que a pandemia já provocou e ainda trará novas transformações para a educação, destacando que os modelos até então adotados não atendem mais às demandas da nova realidade. Isto posto, cabe repensar o âmbito educativo para o contexto pós-pandemia, visto que a perspectiva de retorno ao presencial poderá envolver práticas híbridas, demandando investimentos em formação e transformação nos currículos e na estrutura das instituições.

\section{Considerações finais}

O necessário distanciamento físico, instaurado com a pandemia da COVID19, levou à suspensão de atividades envolvendo grandes grupos em um mesmo ambiente, dentre elas, as aulas presenciais, de maneira que os professores têm atuado em contextos remotos. Dessa forma, neste estudo, investigamos as experiências docentes na nova modalidade, destacando situações problemáticas e aspectos que têm contribuído para promover melhorias nas práticas pedagógicas.

Os resultados apontam que, apesar dos desafios do primeiro impacto, no qual os docentes vivenciaram situações problema envolvendo a descoberta de quais recursos adotar e como inseri-los em seu planejamento, de maneira a atender às necessidades dos seus alunos, os professores vêm se adaptando gradativamente ao novo contexto.

Além do acompanhamento das instituições com momentos formativos, estudos autônomos têm auxiliado os docentes a superarem seus desafios, principalmente aqueles que envolvem a apropriação de recursos e interfaces para subsidiar suas aulas. No entanto, problemas de conexão e participação dos alunos nas aulas ainda demandam soluções.

Como aspectos positivos da nova modalidade, os participantes da pesquisa enfatizam o fato de terem descoberto novas interfaces, atualizando suas práticas em consonância com a realidade dos aprendizes da cultura digital, além de estarem utilizando recursos lúdicos, como vídeo, músicas e jogos com maior incidência, uma vez que o uso destes materiais ficou mais simples, bastando o compartilhamento de tela com os alunos.

Ao perceber que a carência de formação para uso das tecnologias digitais com fins pedagógicos configurou-se como um grande desafio a ser enfrentado pelos docentes, faz-se pertinente maiores investimentos neste âmbito, ao tempo em que políticas públicas de implementação de acesso às tecnologias e internet de qualidade sejam intensificadas, uma vez que o retorno às atividades educativas totalmente presenciais ainda é desconhecido e que a 
mediação tecnológica em instâncias diversas é uma realidade que se instaurou com a cultura digital, ou seja, com a cultura que vivenciamos atualmente.

\section{Referências}

ALVES, Lynn. Educação Remota: Entre a ilusão e a realidade. Interfaces Científicas, v. 8, n. 3, p. 348- 365, 2020. Disponível em:

https://periodicos.set.edu.br/index.php/educacao/article/view/9251 . Acesso em: 10 jul. 2020.

ARRUDA, Eucidio Pimenta. EDUCAÇÃO REMOTA EMERGENCIAL: elementos para políticas públicas na educação brasileira em tempos de Covid-19. EmRede, v. 7, n. 1, p. 257 $275,2020$.

BORGES, Elaine Ferreira do Vale; PAIVA, Vera Lucia Menezes de Oliveira. Por uma abordagem complexa de ensino de línguas. Linguagem \& Ensino, Pelotas, v. 14, n. 2, p. 337-356, jul./dez. 2011.

BRASIL. Decreto no 5.622, de 19 de dezembro de 2005. Regulamenta o art. 80 da Lei no 9.394, de 20 dezembro de 1996, que estabelece as diretrizes e bases da educação nacional. Disponível em: http://portal.mec.gov.br/seed/arquivos/pdf/dec 5622. Acesso em: 25 jul. 2020.

BRASIL. Ministério de Educação e Cultura. LDB. Lei n 9394/96, de 20 de dezembro de 1996. Estabelece as diretrizes e bases da Educação Nacional. Brasília: MEC, 1996.

Disponível em: http://www.planalto.gov.br/ccivil_03/leis/19394.htm. Acesso em: 25 jul. 2020.

BRASIL. Ministério da Educação. Portaria n 544, de 16 de junho de 2020. In: Diário Oficial da União. Brasilia: DOU, 2020. [Dispõe sobre a substituição das aulas presenciais por aulas em meios digitais, enquanto durar a situação de pandemia do novo coronavírus - Covid19, e revoga as Portarias MEC $\mathrm{n}^{\circ} 343$, de 17 de março de 2020, $\mathrm{n}^{\circ} 345$, de 19 de março de 2020, e $\mathrm{n}^{\mathrm{o}} 473$, de 12 de maio de 2020.] http://www.in.gov.br/en/web/dou/-/portaria-n-544de-16-de-junho-de-2020-261924872 . Acesso em: 16 jul. 2020.

CAMPUS, Fernanda. A educação em tempos de pandemia. Observatório da comunicação Institucional. Jun. 2020. Disponível em: https://observatoriodacomunicacao.org.br/colunas/aeducacao-em-tempos-de-pandemia-por-fernanda-campos/\#disqus_thread. Acesso em: 2 jul. 2020.

CIEB: notas técnicas \#17:estratégias de aprendizagem remota (EAR): características e diferenciação da educação a distância (EAD) [recurso eletrônico]. São Paulo: Centro de Inovação para a Educação Brasileira-CIEB, 2020.

CNN Brasil. Demissão de professores vira rotina em universidades de São Paulo. Matéria da CNN Brasil em 4 de julho de 2020. Disponível em:

https://www.cnnbrasil.com.br/nacional/2020/07/04/demissoes-de-professores-vira-rotina-emuniversidades-de-sao-paulo. Acesso em: 5 jul. 2020. 
CONSELHO NACIONAL DE EDUCAÇÃO. Parecer CNE/CP N:9/2020. Conselho Nacional de Educação. Ministério da Educação, 2020.

Reexame do Parecer $\mathrm{CNE} / \mathrm{CP} \mathrm{n}^{\mathrm{o}}$ 5/2020, que tratou da reorganização do Calendário Escolar e da possibilidade de cômputo de atividades não presenciais para fins de cumprimento da carga horária mínima anual, em razão da Pandemia da COVID-19] http://portal.mec.gov.br/index.php?option $=$ com_docman\&view $=$ download\&alias $=147041$ pcp009-20\&category_slug=junho-2020-pdf\&Itemid=30192 . Acesso em: 25 jul. 2020.

COUTO, Edvaldo Souza; COUTO, Edilece Souza; CRUZ, Ingrid de Magalhães Porto. \#Fiqueemcasa: educação na pandemia da covid-19. Interfaces Científicas. Aracaju. v. 8, n. 3, p. $200-217,2020$.

DEMO, Pedro. Educar pela pesquisa. Campinas, SP: Autores Associados, 1996.

EL País. Em meio à pandemia fomos tratados como números. Matéria do EL País em 24 de junho de 2020. Disponível em https://brasil.elpais.com/brasil/2020-06-24/em-meio-apandemia-fomos-tratados-como-numeros-diz-professor-demitido-da-uninove.html . Acesso em: 30 jun. 2020.

FINARDI, Kyria Rebecca; PORCINO, Maria Carolina. Tecnologia e metodologia no ensino de inglês. Ilha do Desterro. Florianópolis, n. 66, p. 239-282, jan/jun 2014.

FREENET, Documentário. Direção Pedro Ekman. Produção: Juliana Bruce, 2016. Disponível em https://libreflix.org/assistir/freenet . Acesso em: 25 jun. 2020.

HENRIQUE, Trazíbulo. COVID-19 e a INTERNET (OU ESTOU EM ISOLAMENTO SOCIAL FÍSICO). Interfaces Científicas, v.8, n. 3, p. 5-8, 2020. Disponível em: https://periodicos.set.edu.br/index.php/humanas/article/view/8713. Acesso em: 7 jul. 2020.

MOREIRA, José António; SCHLEMMER, Eliane. Por um novo conceito e paradigma de educação digital onlife. Revista UFG, v. 20, p. 1-35, 2020.

PAIVA, Vera Lúcia Menezes. O uso da Tecnologia no ensino de línguas estrangeiras: breve retrospectiva histórica. In: JESUS, Daniel Macedo; MACIEL, Ruberval Franco (Orgs.).

Olhares sobre tecnologias digitais: linguagens, ensino, formação e prática docente: Coleção Novas perspectivas em Linguística Aplicada. v. 44, Campinas, SP: Pontes Editores, 2015, p. 21-34.

Pesquisa TIC domicílios 2019, disponível em:

https://www.cetic.br/media/analises/tic_domicilios_2019_coletiva_imprensa.pdf. Acesso em: 3 jul. 2020.

PRETTO, Nelson De Luca; BONILLA, Maria Helena Silveira; SENA, Ivânia Paula F. S. (Orgs.). Educação em tempos de pandemia: reflexões sobre as implicações do isolamento físicos imposto pela COVID-19. Salvador: Edição do autor, 2020. 
RAIMUNDO, Clarice Maria; SILVEIRA, Karin Raphaella. Ensino de línguas estrangeiras, mídias digitais e pensamento complexo. Anais do XIV Congresso Nacional de Educação EDUCERE, 2017.

SANTOS, Edméa. Pesquisa-formação na cibercultura. Teresina: EDUFPI, 2019.

SANTOS, Edméa. EAD, palavra proibida. Educação online, pouca gente sabe o que é. Ensino remoto, o que temos para hoje. Mas qual é mesmo a diferença? \#livesdejunho... REDOCrevista docência na cibercultura, 2020. Disponível em: https://www.epublicacoes.uerj.br/index.php/re-doc/announcement/view/1119. Acesso em: 12 jul. 2020.

SANTOS, Annie Rose; BURCI, Taissa V. Lozano. O desenvolvimento histórico das tecnologias. In: COSTA, Maria Luisa Furlan; SANTOS, Annie Rose (Orgs.). Educação e novas tecnologias: Questões teóricas, políticas e práticas. Maringá: Eduem, 2017, p. 13-27.

YIN, R. K. Case study research: Design and methods. California: Sage publication, Thousand Oaks, 2003. 